\title{
Impact Assessment of Exclusive Breastfeeding Media Campaign Among Mothers in Selected Metropolitan Cities in South East Nigeria
}

\author{
${ }^{1 *}$ Samuel O. Chukwu-Okoronkwo, ${ }^{2}$ Uzoma C. Okugo, $\quad{ }^{3}$ Innocent P. Ihechu and ${ }^{4}$ Nnenna E. Okoronkwo \\ ${ }^{1,2,3}$ Department of Mass Communication, Faculty of Humanities and Social Sciences, Abia State University, \\ Uturu, Nigeria. \\ ${ }^{4}$ Department of Pure and Industrial Chemistry, Faculty of Biological and Physical Sciences, Abia State \\ University, Uturu, Nigeria.
}

This research is funded by Tertiary Education Trust Fund (TETFund) of the Federal Government of Nigeria through Abia State University, Uturu, Nigeria.

\section{Abstract}

Unarguably, the mass media by virtue of their information dissemination function play vital role in communication for health and sustainable development of the society. Health communication involves the study and use of communication strategies to inform and influence individuals and community decisions in enhancing healthy living. Therefore, the health sector, like any given sector of the society, shares a remarkable and unalienable relationship with the mass media, as evidenced through the radio, television, newspapers and magazines, among others, in communicating health policies, reporting activities in the health sector, embarking on health campaigns and in publicizing health programmes. The study is an impact assessment of exclusive breastfeeding media campaign among mothers in selected metropolitan cities in South East Nigeria to ascertain their disposition to exclusive breastfeeding media campaign messages amidst prevailing lack of interest among majority of mothers in upholding this auspicious agelong practice which invariably impacts on the wellbeing of the infant child, perhaps as a result of ignorance and lack of education, among other social factors. Qualitative and quantitative (mixed) research approaches were employed in this study. Findings reveal evident positive impact of exclusive breastfeeding media campaign messages on mother in South East Nigeria. However, antenatal channel rather than the traditional media channels remains the major source of information to mothers on exclusive breastfeeding practice in the region. The study, therefore, strongly affirms that much more is still required from the traditional media platforms especially in terms of enlivened programme design and committed publicity to rightly occupy their place in this campaign role considering the heterogeneous nature of the audience they serve, which predisposes them more advantageous to reach even prospective mothers (those not yet expecting babies) who may not have immediate need to come for antenatal to access such beneficial nutritional and health information.

Key words: exclusive breastfeeding, health communication, media campaign, mothers, South East Nigeria, sustainable development

DOI: $10.7176 /$ RHSS/9-14-16

Publication date:July $31^{\text {st }} 2019$

\subsection{INTRODUCTION}

Breastfeeding is the natural form of infant feeding for humans (mammals) providing the main source of nutrients within the first few months of life (Savino, 2008). It has been identified as the healthiest and safe way to feed babies, as it contains complete nutritional composition essential to fully satisfy the nutritional needs of the infant and children (Oddy, 2002; Ibe and Nkanginieme, 1990). Experts' perception of breastfeeding, therefore, as the best source of infant nutrition and immunologic protection, which also provides remarkable health benefits to mothers, cannot be overemphasized. It is has remained an exceptional means of providing ideal food for the healthy growth and development of infants; and thus regarded as an integral part of the reproductive process with important implications for the health of mothers. Little wonder why Kathleen Sebelius, Secretary to U.S. Department of Health and Human Services, has hinted that besides contributing to the mutual bonding between mothers and babies, breastfeeding is essentially important to mothers' and infants' health.

Furthermore, studies have shown that exclusive breastfeeding for six (6) months, therefore, is the most favourable way of infant nutrition, which is also encouraged to be continued even as the infant receives complementary foods thereafter (Victora et al., 2016; AAP, 2012; WHO, 2011; Ashraf et al., 1993). Exclusive breastfeeding is further revealed to reduce the infant mortality associated with common childhood illnesses such as diarrhoea or pneumonia. However, despite the plethora of inherent benefits associated with breastfeeding and exclusive breastfeeding in particular, there exists an apparent prevailing lack of interest among mothers in upholding its practice, owing perhaps to ignorance and lack of education, as well as other social factors. The study is, therefore, concerned with the fact that despite the magnitude of inherent benefits associated with 
breastfeeding, particularly exclusive breastfeeding, to mothers and infants, and by extension society, there still exists an apparent prevailing lack of interest among majority of mothers in upholding this positive agelong practice. This has, therefore, resulted to concerted concern from various stakeholders both nationally and internationally, especially in the light of the accruing dangers the situation portend to infants and mothers, nay society, to stem this ugly tide; which in turn has given rise to the mounting proactive campaigns on the platforms of various media agencies on the need to sustain the agelong practice of breastfeeding, and indeed exclusive breastfeeding, for all its benefits. Focusing on the South East Nigeria, the study assesses the perception of mothers in this region, who appear to be particularly concerned, regarding exclusive breastfeeding, to ascertain their disposition to exclusive breastfeeding media campaign messages, so as to articulate viable recommendations that would not only help in consolidating the accruing gains from these campaigns, but also awaken more favourable attitude towards exclusive breastfeeding practice considering its immense benefits.

\subsection{Objectives of the Study}

The study is premised on the following specific objectives:

i. To determine the general level of awareness of mothers in South East Nigeria on Exclusive Breastfeeding practice.

ii. To ascertain their major source of information regarding Exclusive Breastfeeding.

iii. To determine their collective disposition towards Exclusive Breastfeeding practice.

iv. To find out if their exposure to Exclusive Breastfeeding media campaign messages in any way influenced their positive disposition in that regard, and

v. To determine their level of compliance to WHO's recommended duration for Exclusive Breastfeeding practice.

\subsection{LITERATURE REVIEW}

The mainstay of infants' diet in every culture from time immemorial had been breast milk. It is a postnatal activity of paramount importance and interest to diverse professionals in pediatrics, nursing endocrinology, psychology as well as sociology and anthropology (Uwakwe, 1996). With time, however, the trend began to change as majority of mothers no longer breastfeed their babies as supposed. Unfortunately, therefore, breastfeeding has gone from the main source of food for infants to an uncomfortable less used practice (Wiese Erin, 2005). A critical assessment of this worrisome trend could be linked to the rising trend in civilization and the evolution of new cultural ideals (Eliot, 2003), by which breastfeeding has now been branded as old-fashioned and uncivilized. Besides the rising trend in civilization accounting for the decrease in breastfeeding rates, the effect of social perceptions (Bunik et al., 2006; Li et al., 2004; Raisler, 2000) as well as lack of education or knowledge (Gibson, 2005; Dennis, 2002) has also tremendously contributed to many more women neglecting the breastfeeding practice. Ann and Richard (2001) unequivocally attributed this ugly development to poor emphasis on the benefits of breastfeeding and the popularity of synthetic baby formulations. Further limitations to improved breastfeeding practices besides other prevailing myths include:

- Complacency, which may be one of the biggest threats to optimal infant feeding

- Widespread promotion of breast-milk substitutes

- Belief that infants need water in addition to breast milk

- The issue of breastfeeding and HIV transmission

- Lack of support for breastfeeding at home, in the community, in health care facilities and in workplaces (e.g., policies for maternity leave and worksite facilities for breastfeeding), linked to the perception that behaviour change is difficult or even impossible

- Lack of commitment and resources for behaviour change programmes needed to support optimum breastfeeding, and

- $\quad$ Poor understanding of the role of breastfeeding in advancing human and health rights (UNESCO, 2006, p.8)

However, breastfeeding remains the best source of infant nutrition and immunologic protection, which also provides remarkable health benefits to mothers (Victora et al., 2016; AAP, 2012; Setegn et al., 2012; WHO, 2011). Similarly, the World Health Organisation $(2001 ; 2009)$ hints that exclusive breastfeeding is the single most cost-effective intervention to reduce infant mortality in developing countries. The 1990 Innocenti Declaration on the Protection, Promotion and Support of Breastfeeding maintain that breastfeeding alone provides the ideal nourishment for infants for the first six months of life because it contains all the water, nutrients, antibodies and other factors an infant needs in order to thrive. Thus, it has profound impact on a child's survival, health, nutrition and development. It is an exceptional means of providing ideal food for the healthy 
growth and development of infants. Kathleen Sebelius, Secretary to U.S. Department of Health and Human Services, has hinted that besides contributing to the mutual bonding between mothers and babies, breastfeeding is essentially important to mothers' and infants' health. A UNICEF (2015) document emphasized that the interaction between the mother and child during breastfeeding has positive effects for life for the child, in terms of stimulation, behaviour, speech, sense of wellbeing and security and how the child relates to other people. It also lowers the risk of chronic conditions later in life, such as obesity, high cholesterol, high blood pressure, diabetes, childhood asthma and childhood leukaemias; and enables infants do better on intelligence and behaviour tests into adulthood than formula-fed babies. Breastfeeding also contributes to maternal health immediately after the delivery because it helps reduce the risk of post-partum haemorrhage. In the short term, it delays the return to fertility and in the long term, it reduces the risk of type 2 diabetes and breast, uterine and ovarian cancer.

Furthermore, studies have also shown that exclusive breastfeeding for six months is the most favorable way of infant nutrition Victora et al., 2016; AAP, 2012; Setegn et al., 2012; WHO, 2011). Exclusive breastfeeding, wherein the infant only receives breast milk without any additional food or drink, not even water, as WHO (2011) and AAP (2012) recommended, is further revealed to reduce the infant mortality associated with common childhood illnesses such as diarrhoea or pneumonia. This is as a result of the fact that breast milk carries antibodies from the mother that help combat disease. Morse (1992) has stated that, breast milk contains fat which helps in rapid development of the brain of the child. Due to colostrums in breast milk, the baby acquires immunity against infection, gets nutrients for physical and mental development, emotional security and closeness to the mother. As a dynamic and physiologically sensitive process, breast milk production is adjusted to suit the infant's requirement according to environmental changes. For example, breast milk will contain more fat during cold seasons. The mother also benefits from Exclusive Breastfeeding (EBF), to reinforce UNICEF's earlier emphasis, by experiencing lactation amenorrhea, fast return of the uterus to its normal size, prevention of post partrum haemorrhage, reduced risk of getting cancer of the breast and ovary, low risk of osteoporosis and emotional satisfaction (Ramos, 1996).

\subsection{Benefits of Exclusive Breastfeeding}

An overview of the benefits of exclusive breastfeeding for infants and mothers as contained in a UNESCO (2006, p.8) Communication for Development initiative in infant and young child feeding Programmes reveals as follows:

\subsubsection{Benefits for infants:}

- Provides adequate water for hydration.

- Provides superior nutrition for optimum growth.

- Protects against infection and reduces overall child mortality. The biggest impact on reducing illness relates to diarrhoea, through two mechanisms:

(1) reduced risk of bacteria from contaminated formula, other liquids and foods, and

(2) transfer of antibodies through breast milk.

- $\quad$ Reduces overall neonatal mortality by around 20\% (early initiation of breastfeeding).

- Promotes bonding and development.

- Results in better cognitive development and IQ than in formula-fed children.

- Lowers the risk of chronic conditions such as diabetes, heart disease, obesity, certain cancers etc. compared with formula-fed infants.

\subsubsection{Benefits for mothers:}

- (Early initiation) helps contract the uterus, expel the placenta and reduce bleeding.

- Helps mothers return more rapidly to their pre-pregnancy weight and a lower body mass index after 5-6 years.

- Lowers risk of pre-menopausal breast cancer and ovarian cancer.

- May delay return of fertility.

\subsubsection{Benefits for society:}

- Lowers family food and health expenditures.

- Decreases workforce absence due to decreased infant and maternal illness.

- Lowers health care provider costs due to decreased infant and maternal illness, staff time, kitchen requirements, space, nursery beds, etc.

- Is a basic human right and may help bridge the divide between marginalized and 
vulnerable populations and more privileged groups.

It is obvious from the foregoing analysis that the health benefits of breastfeeding and exclusive breastfeeding in particular to infants and mothers, and indeed the society by extension, cannot be overemphasized. Breastfeeding is invariably an environmental health practice. Particularly in the light of the foregoing benefits of exclusive breastfeeding practice, therefore, it is only instructive to cite Setegn et al. 's 2017 report of the evidence which showed that out of the sixty percent of under-five mortality caused by malnutrition (directly or indirectly), more than two-thirds were associated with inappropriate breastfeeding practices during infancy. Setegn et al., anchoring on other corroborating studies which maintain that not more than $35 \%$ of infants worldwide are exclusively breastfed during their first four months of life; irrespective of the six months' WHO recommended standard, further substantiated their position above. This arising worrisome development, perhaps, is as a result of the wide range of variation both in the understanding and practice of exclusive breastfeeding among mothers, especially in developing countries, with the following cited documented rates:

- $\quad$ Brazil (58\%)

- $\quad$ Bangalore $(40 \%)$

- $\quad$ Iran (Zahedan) (69\%)

- $\operatorname{Iran}(28 \%)$

- Beruwala (Kalutara) $(15.5 \%)$

- Lebanon (10.1\%)

- Nigeria (20\%)

- Bangladesh (34.5\%)

- Jordan (77\%)

- Ethiopia (49\%)

(Setegn et al., 2017, p.2)

\subsection{The Role of Mass Media in Communication for Health and Development in the Society}

The mass media, indeed, play a vital role in communication for health and sustainable development in any society. This is obviously as a result of their information dissemination function, by which they interact with all other social institutions in the society. Ineji (2003) reinforces the foregoing by stressing that the mass media function within each of the social systems to foster interaction, exchange and sustenance of society. The health sector like any other sector of the society, shares a relationship with the mass media. This is realized through the radio, television, newspapers and magazines, among others, which communicate health policies, report activities in the health sector, embark on health campaigns and publicize health programmes among other functions, which have invariably produced changes in certain behavioural practices (Hornik, 1985). It is now known that the best use of media, particularly for stand-alone media campaigns, is to build public awareness about a new issue, problem, or resolution. Thus the media remain very powerful instrument of setting public's agenda, by shaping what people view as important in the world, as well as identifying and defining concerns, issues and problems. The implication of the foregoing in relation to our context is that in the light of the prevalence of many more women neglecting exclusive breastfeeding practice, the mass media have risen to the challenge of their invaluable role in serving as indisputable attitudinal/behavioural change agents in communicating exclusive breastfeeding campaign messages in conditioning and reorienting the consciousness of mothers in South East Nigeria towards the adoption and sustenance of healthy attitude towards the practice, given its immense health benefits both to infants, mothers and the society at large. More so, Chukwu-Okoronkwo and Okoronkwo (2017) may have shed more light on the necessity of exclusive breastfeeding media campaign as touching the wellbeing of the infant child by drawing our attention to the growing "consciousness of the significant position of children in the family and society as the future generation, leaders of tomorrow and potential flag-bearers of any nation, who need to be properly cared for and nurtured...to develop their potentials for such enormous responsibilities" ahead of them (1). This is borne out of the belief that with much awareness campaign, the breastfeeding, and indeed exclusive breastfeeding culture, will witness a strong revival among women in Southeast Nigeria.

\subsection{METHODOLOGY}

Considering the nature of the study, the researchers adopted simple random sampling (by selecting two (2) major towns in each of the five (5) states in South East Nigeria), case study, content analysis and administration of questionnaire approaches of the mixed method of research in order to provide appropriate insight into the problem of the study and the exploration of its possible resolution. The breakdown of the selection designating the states and cities is as follows: Abia State, comprising Umuahia and Aba; Anambra State, comprising Awka 
and Onitsha; Ebonyi State, comprising Abakaliki and Afikpo; Enugu State, comprising Enugu and Nsukka; and Imo State, comprising Owerri and Okigwe. Questionnaire was carefully designed in line with the objectives of the study and subsequently administered to mothers in the selected cities. Their responses were collated and further used for analysis.

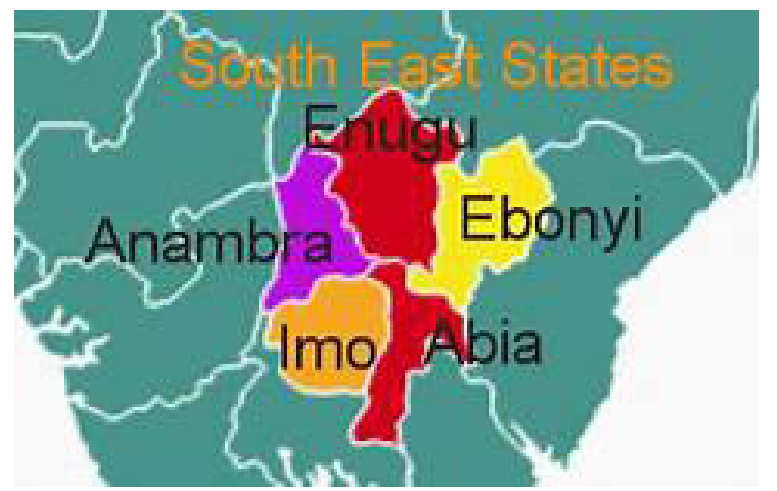

Map showing the area of study - the five (5) South East states in Nigerian Source: www.vanguardngr.com

\subsection{RESULTS AND ANALYSIS}
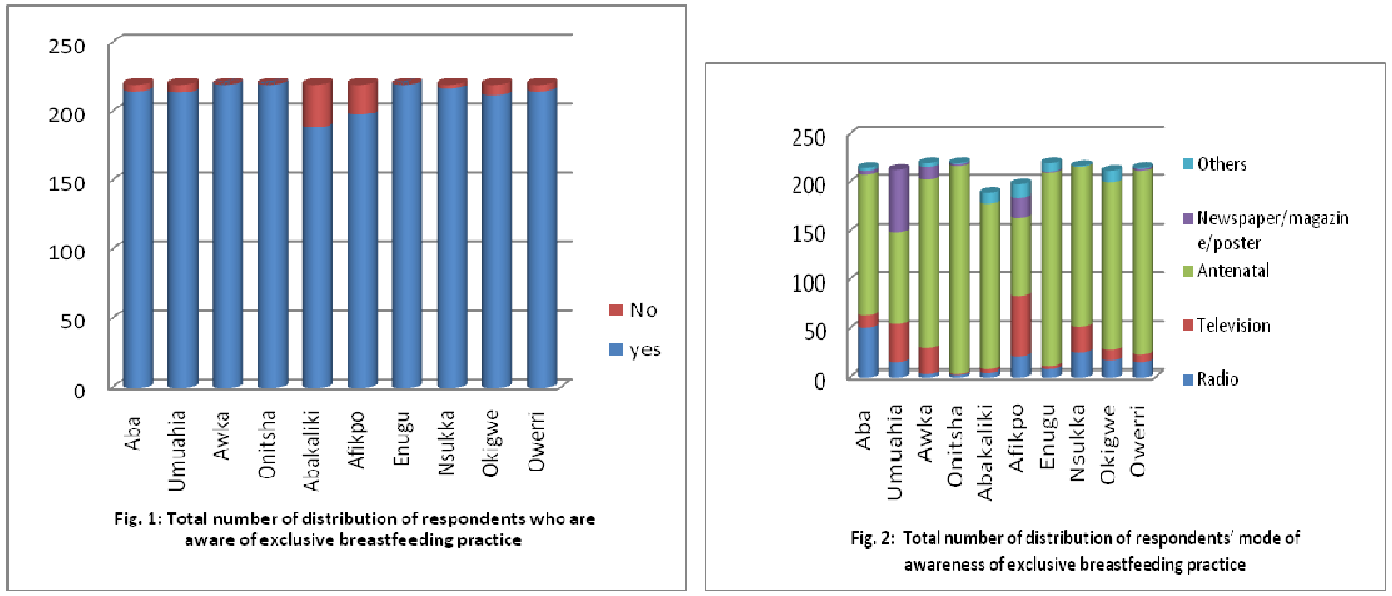

In figure 1, out of 220 respondents selected for study in each of the ten locations, numbering a sum total of 2200 , those that responded either in the affirmative or negative to the inquest on awareness of exclusive breastfeeding practice are represented as follows: from Abia - in Aba, a major commercial city of the state, 215 responded in the affirmative while 5 responded in the negative, and in Umuahia the state capital, 214 responded in the affirmative while 6 responded in the negative; from Anambra - all the 220 respondents in Awka the capital city and Onitsha, a major commercial city of the state, respectively were unanimously in the affirmative; Ebonyi - in Abakaliki the state capital, 189 responded in the affirmative while 31 responded in the negative, and in Afikpo, a major city of state, while 198 responded in the affirmative, 22 responded in the negative; Enugu - in Enugu the state capital, all the 220 respondents were in the affirmative and in Nsukka, a major city of the state, while 217 responded in the affirmative, 3 responded in the negative; Imo - in Okigwe, a major city of the state, 212 respondents were in the affirmative while 8 were in the negative, and in Owerri the state capital, 215 respondents were in the affirmative while 5 were in the negative. From the above analysis, out of a total number of 2200 respondents reached, a sum total of 2120 were in affirmative of their awareness of exclusive breastfeeding practice, while a sum total of 80 were in the negative. Hence, it was the sum total of the 2120 respondents in affirmative that formed the concentration of the researchers in the study. Figure 2, therefore, represents the distribution of respondents' mode of awareness of exclusive breastfeeding practice and shows that overwhelming majority of the respondents learnt about exclusive breastfeeding practice through antenatal, while less significant others learnt from either radio or television medium; only very few respondents learnt about exclusive 
breastfeeding practice from print sources, including newspapers, magazines and posters. Further details of fig. 2 is presented in the table below:

\begin{tabular}{|c|c|c|c|c|c|c|c|c|c|c|}
\hline \multirow{2}{*}{ Response } & \multicolumn{2}{|c|}{ Abia } & \multicolumn{2}{|c|}{ Anambra } & \multicolumn{2}{|c|}{ Ebonyi } & \multicolumn{2}{|c|}{ Enugu } & \multicolumn{2}{|c|}{ Imo } \\
\hline & Aba & $\begin{array}{l}\text { Umuahi } \\
\text { a }\end{array}$ & Awka & Onitsha & $\begin{array}{l}\text { Abakali } \\
\text { ki }\end{array}$ & $\begin{array}{l}\text { Afikp } \\
\text { o }\end{array}$ & $\begin{array}{l}\text { Enug } \\
\text { u }\end{array}$ & $\begin{array}{l}\text { Nsukk } \\
\text { a }\end{array}$ & Okigwe & $\begin{array}{l}\text { Ower } \\
\text { ri }\end{array}$ \\
\hline Radio & 51 & 15 & 04 & 03 & 05 & 21 & 08 & 25 & 17 & 15 \\
\hline Television & 13 & 40 & 26 & 01 & 03 & 63 & 03 & 27 & 11 & 08 \\
\hline Antenatal & 144 & 94 & 173 & 213 & 171 & 80 & 199 & 164 & 172 & 189 \\
\hline $\begin{array}{l}\text { News } \\
\text { paper/ } \\
\text { magazine/ } \\
\text { poster }\end{array}$ & 04 & 64 & 13 & 02 & - & 21 & 01 & - & - & 02 \\
\hline Others & 03 & 01 & 04 & 01 & 10 & 13 & 09 & 01 & 12 & 01 \\
\hline Total & 215 & 214 & 220 & 220 & 189 & 198 & 220 & 217 & 212 & 215 \\
\hline
\end{tabular}

Table 1: Further details of fig. 2 above
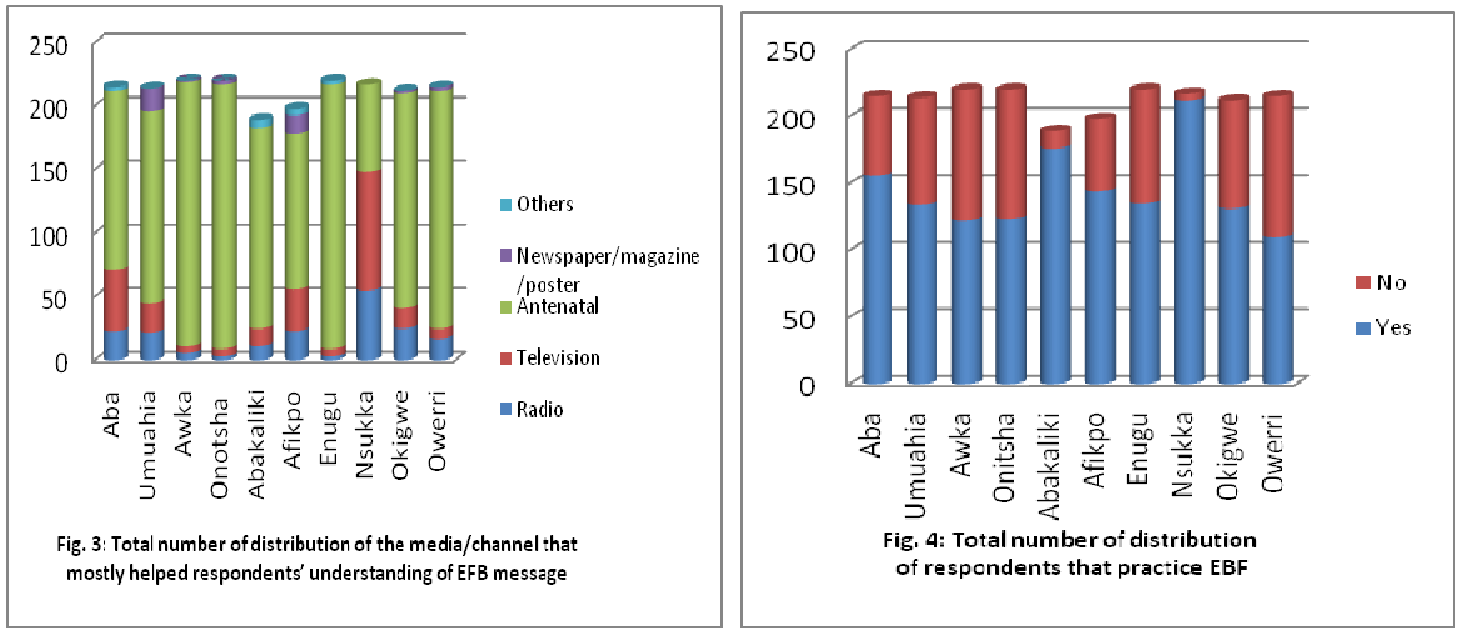

Figure 3 reveals that antenatal has helped majority of the respondents to understand breastfeeding messages more than radio and television as well as the print media. Figure 4 shows that in all the locations of the study, the numbers of respondents that practice EBF are more than those who do not.

Fig. 5: Total number of distribution of respondents'


Figure 5 reveals that with the exception of insignificant few, majority of the respondents understand that exclusive breastfeeding is the feeding of breast milk only to the infant child from $0-6$ months. However, Figure 6 shows that majority of the respondents were significantly influenced by antenatal rather the conventional media in their practice of exclusive breastfeeding.

The study, therefore, yielded the following summarized findings:

i. There is general awareness of mothers in South East Nigeria on exclusive breastfeeding practice.

ii. This awareness is partly from media campaigns (in the traditional or rather conventional media - radio, television and print), and few other sources.

iii. Greater awareness, however, is gained by these mothers from antenatal (rather than the traditional media) and any other source.

iv. Majority of the mothers identify with exclusive breastfeeding practice.

v. Most mothers though did not embrace the practice holistically, as they did not comply with the 0 6months' WHO standard/recommendation.

vi. However, an overwhelming majority of the mothers affirm that exclusive breastfeeding affords children immunity against early childhood diseases and that babies exclusively breastfed look healthier than babies fed on artificial milk.

vii. Lastly, the mothers do not only consider exclusive breastfeeding as best source of nutrition for infants, but were readily disposed to recommend it to all nursing mothers because of its invaluable health benefits.

\subsection{CONCLUSION}

Consequent upon the foregoing findings, the study strongly affirms that the health benefits of exclusive breastfeeding practice both for infants and mothers as propagated through media campaigns cannot be overemphasized. However, it is evident from the study that the major source of information to mothers about exclusive breastfeeding practice is from antenatal (message dissemination channel) rather than the traditional media - radio, television and print. Hence, there is an expedient need to determinedly rise to the challenge and properly address this apparent underperformance to effective realization of the noble and worthy objectives of exclusive breastfeeding media campaigns.

\subsection{RECOMMENDATIONS}

Considering the identified shortfall on the part of the traditional mass media in taking the lead role in propagating exclusive breastfeeding messages as study shows, if they must effectively play their vital role in communication for health and sustainable development in the society, particularly about exclusive breastfeeding practice in South East Nigeria, the study recommends that they, especially the broadcast platforms, should do more in term of enlivened programme design and time allocation to rightly occupy their place in this direction considering the heterogeneous nature of the audience they serve, which predisposes them more advantageous to reach even potential mothers (those not yet expecting babies) who may not have immediate need to come for antenatal to access such beneficial nutritional and health information. Furthermore, there is also need to find possible ways of collaborating with the health centres, since they have proven to be viable sources of disseminating exclusive breastfeeding messages, as to incorporate such collaboration feedback/report as part of their media campaigns strategies, and indeed, a much more robust communication for health approach in these campaigns, for effective and sustainable results.

\section{Acknowledgements}

The authors are very grateful to the management of Abia State University, Uturu, Nigeria for facilitating the research project that gave rise to this report, as well as the Tertiary Education Trust Fund (TETFund) of the Federal Government of Nigeria for funding it. Their sustained commitment to the promotion of academic research excellence is highly appreciated.

\section{References}

American Academy of Pediatrics [AAP] (2012). "Policy statement: Breastfeeding and the use of human milk". Pediatrics; Volume129:e827- e841.

Ann, L. W. \& Richard, J. S. (2001). "The resurgence of breastfeeding at the end of second millennium". Pediatrics, 103(2): $531-542$.

Ashraf, R. N.; Jalil, F.; Aperia, A. \& Lindblad, B. S. (1993). "Additional water is not needed for healthy babies in a hot climate". Acta Paediatr; 82: 1007 - 1011. 
Bunik, M., Clark, L., Zimmer, L. M., Jimenez, L. M., O’Connor, M. E., Crane, L. A., \& Kempe, A. (2006). Early infant feeding decisions in low-income Latinas. Breastfeeding Medicine, 1(4), 225-235.

Chukwu-Okoronkwo Samuel O. and Okoronkwo Nnenna E. (2017). "Child abuse and prostitution phenomena: Critical issues in Nigeria's sustainable development", American Journal of Environment and Sustainable Development, Vol. 2, No. 3: 16 - 22.

Diane, M. F., Margaret, A. C., \& Anna, F. W. (2006), Myles Textbook for Midwives. African Edition. London: Elsevier Limited.

Dennis, C. (2002). "Breastfeeding initiation and duration: A 1990-2000 literature review". Journal of Obstetric Gynaecologic and Neonatal Nursing, 32(1): 12 - 32.

Eliot, J. (2003). Breastfeeding could save lives. Oxford: Oxford University Press

Gibson, M. E. (2005). "Getting back to basics: The curious history of breastfeeding in the United States", $A m J$ Nursing; 105: 72c-73c.

Hornik, R. (1985). Nutrition Education: A State of the Art Review. Nutrition Policy Discussion Paper 1. Rome, FAO. (ACC/SCN Secretariat).

Ibe, B. C. \& Nkanginieme, K. E. O. (1990). "Breastfeeding in a developing country: Influence of maternal time spent away from child on duration of breastfeeding". Orient Journal of Medicine; 2(2): 56 - 59.

Ineji, U. P. (2003). Mass communication studies: The basics. Calabar: Ushie Printers and Publishing Company Ltd.

Li, R.; Hsia, J.; Fridinger, F.; Hussain, A.; Benton-Davis, S.; \& Grummer-Strawn, L. (2004). "Public beliefs about breastfeeding policies in various settings". J Am Diet Assoc.; 104(7):1162-1168.

Morse, J. M. \& Ewing, G. (1992). "The effect of maternal fluid intake on breast milk supply: A pilot study". Canadian Journal of Public Health 83(3):213-216.

Oddy, W. H. (2002). The impact of breastfeeding on infant and child health. Breastfeeding Review: 5-18.

Raisler, J. (2000). Against all odds: Breastfeeding experience of low income mothers. Wisconsin: Wisconsin Press.

Ramos, R. \& Kennedy, K. I. (1996). "Effectiveness of lactational amenorrhoea in prevention of pregnancy in Manila, the Philippines: Non-comparative prospective trial”. British Medical Journal 313:909-912.

Setegn, T.; Belachew, T.; Gerbaba, M.; Deribe, K.; Deribew, A. \& Biadgilign, S. (2012). "Factors associated with exclusive breastfeeding practices among mothers in Goba district, south east Ethiopia: A cross-sectional study". International Breastfeeding Journal, 7(17): 1 - 8.

The Map of South East States of Nigeria indicating area of study is accessed on September 15 , 2017 from https://www.vanguardngr.com/2017/09/abia-11-not-tolerate-undemocratic-military-operatinons-south-east-igboreps/

UNICEF (2015). Nutrition: Breastfeeding. Accessed on September 12, 2016 from https://www.unicef.org/nutrition/index_24824.html.

UNICEF Web-based Orientation Series for Programme and Communication Specialists (2010). "Improving exclusive breastfeeding practices by using Communication for Development in infant and young child feeding programmes", June 2010 version. 
U.S. Department of Health and Human Services (2011). “The Surgeon General's call to action to support breastfeeding". Washington, DC: U.S. Department of Health and Human Services, Office of the Surgeon General.

Uwakwe, C. B. U. (1996). "The psycho-social determinants of breastfeeding behaviours and practices among nursing mothers in rural urban Nigeria”. Nigerian Journal of Clinical Counselling Psychology, 2: 68 - 80.

Wimmer, R. D. \& Dominick, J. R. (2000). Mass media research: An introduction. Belmont C. A: Wadsworth Publishing Company.

Victora, C. G.; Bahl, R.; Barros, A. J. D.; França, G. V. A.; Horton, S.; Krasevec, J.; Murch, S.; Sankar, M. J.; Neff Walker, \& Nigel C Rollins, N. C. (2016). "Breastfeeding in the 21st century: epidemiology, mechanisms, and lifelong effect". Lancet; 387: 475 - 90.

Wiese, E. (2005). A History of Breastfeeding. Accessed on 7th February, 2016 from www.BF project/A History of Breastfeeding.htm

World Health Organization [WHO] (2011). "The optimal duration of exclusive breastfeeding: Report of an expert consultation". Accessed on May 16, 2016 from hwww.who.int/nutrition/publications/ optimal_duration_of_exc_bfeeding_report_eng.pdf.

World Health Organization [WHO] (2009). Infant and young child feeding (IYCF) Model Chapter for textbooks for medical students and allied health professionals. Switzerland: World Health Organization.

World Health Organization [WHO] (2001). Global strategy for infant and young child feeding. The optimal duration of exclusive breastfeeding. Geneva: World Health Organization.

\section{Note}

The Innocenti Declaration on the Protection, Promotion and Support of Breastfeeding was the outcome of the meeting of a group of world health leaders and technical advisers, concerned by the infant deaths lost from malnutrition and infection due to the lack of optimal infant and young child feeding, at the International Child Development Centre, now known as the Innocenti Research Centre, located in the Spedale degli Innocenti in Florence, Italy in 1990. This declaration invariably underscores the importance of the continuing global efforts towards the overall wellbeing of the infant child, especially with regard to his/her survival, health, nutrition and development, to which exclusive breastfeeding has equally become a key factor. 